
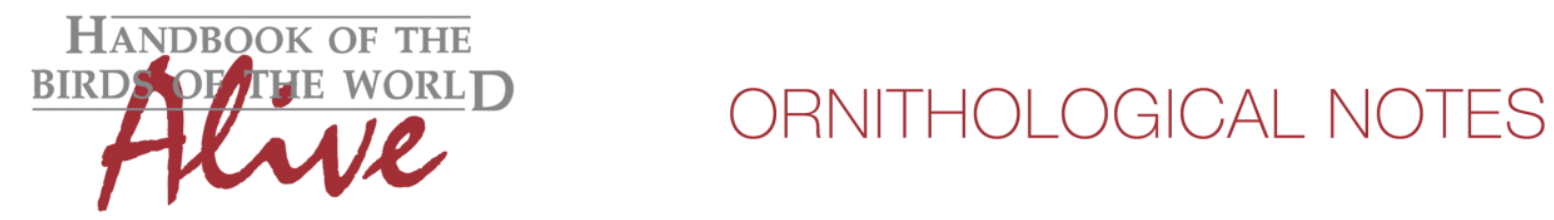

\title{
Notes on the vocalizations of Tropical Pewee (Contopus cinereus)
}

Peter Boesman

In the following we briefly analyze and compare voice of the different races of Tropical Pewee (Contopus cinereus). We also try to quantify the extent of any vocal differences using the criteria proposed by Tobias et al. (2010), as a support for taxonomic review.

We have made use of sound recordings available on-line from Xeno Canto (XC) and Macaulay Library (ML).

There is quite some variation in vocabulary among races. I have therefore inventarised all available recordings on $\mathrm{XC}$ and $\mathrm{ML}$ :

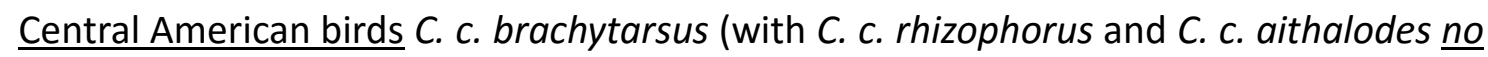
recordings )

1. a trilled "trreereree" (with variations in length, sometimes decelerating at end): 20 recordings

2. a short emphatic upslurred "peek": 6 recordings

3 a short "kit!" (1 rec.) and "peewee" (misidentified?)

Caribbean birds $C$. c. bogotensis and C. c. surinamensis

1. a trilled "treereeree" or "prrreee" (with variations in length, sometimes decelerating at end): 11 recordings

2. a short "pseet": 1 recording

3. a mellow "peeet": 1 recording

Tumbes birds C. c. punensis

1. a whistled "peee-pit": 12 recordings

2. a whistled "peee-peee" or "peee-peee-peee": 9 recordings

3. a single "peee": 2 recordings

4. a trilled "pee-pi-tr": 2 recordings

Southern birds $C$. c. pallescens and C. c. cinereus

1. a whistled "pee!-heew": 14 recordings

2. a repeated "pip..pip..pip..": 22 recordings (incl. wintering birds in SE PEru)

3. a short "psit" (1 rec.) and some interaction trills (1 rec.)

It is clear from this overview that Central American and Caribbean birds, while not identical, share at least the main trilled vocalisation.

If we group these, we keep 3 groups with very different vocalisations. (There may be more vocalisations than what is presently available in the above recordings, and especially dawn songs may still be under-recorded. We will however continue with what we have at present) 

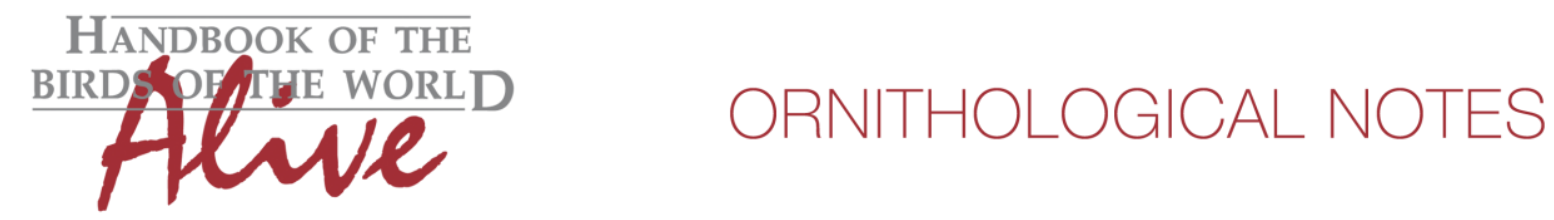

Based a.o. on the number of recordings, it is fair to say that the day-time song for each of the 3 groups is (Fig. 1):

Central American and Caribbean group: a trilled "trreereree"

Tumbes birds: a whistled "pee-pit" or "peee-peee"

Southern birds: a whistled "pee!-heew"
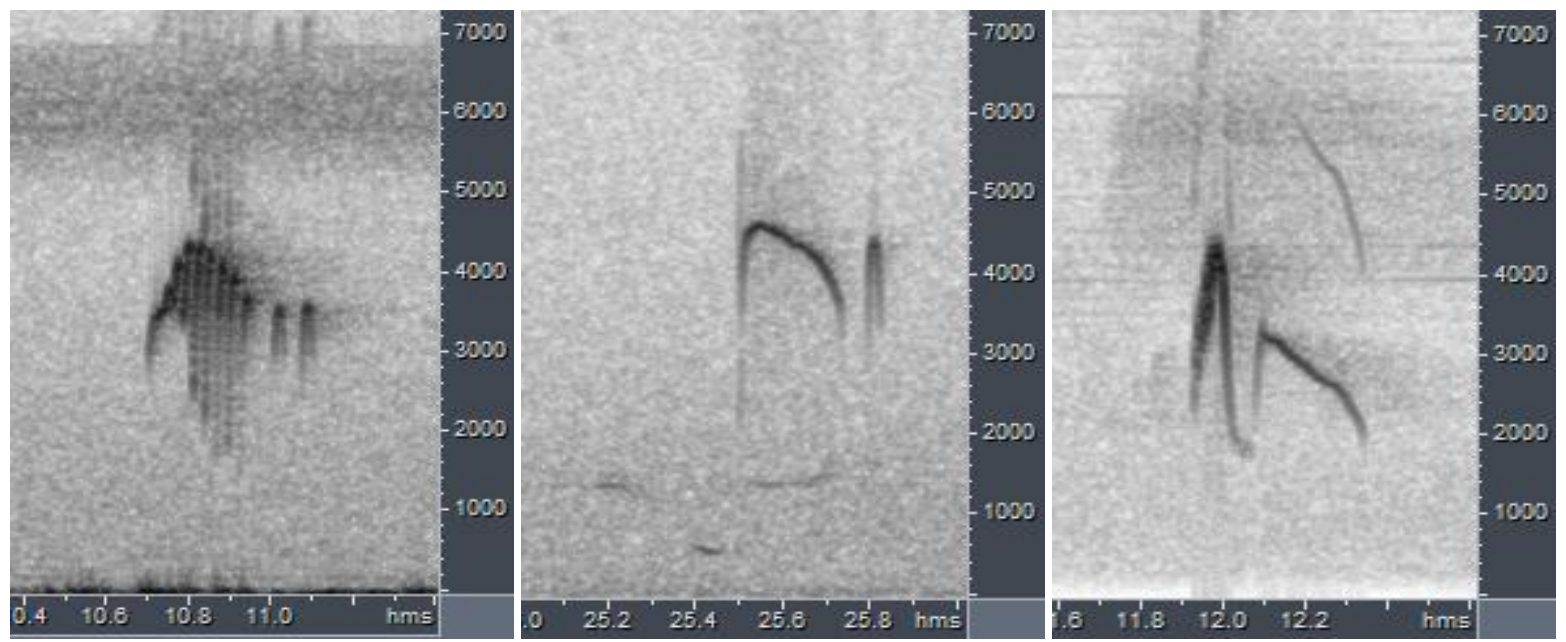

Figure 1: Typical day-time song of Central American and Caribbean group (left), Tumbes group (middle) and Southern group (right)

\section{Measurements:}

group 1: C.Am and Caribbean group: a trilled "trreereree" $(n=7)$

min. freq.

max. freq.

freq. range

longest note

shortest note

\# of notes

total length

min. space
$1860-2700 \mathrm{~Hz}$

$4200-5600 \mathrm{~Hz}$

$1700-3000 \mathrm{~Hz}$

$0.046-0.060 \mathrm{~s}$

$0.025-0.04 \mathrm{~s}$

5-12

$0.28-0.54 \mathrm{~s}$

0.005-0.02s

\section{min. freq.}

max. freq.

freq. range

longest note

shortest note

\# of notes

total length

min. space

group 3: Southern birds: a whistled "pee!-heew" $(n=5)$

$\min$. freq.

max. freq.

freq. range

longest note

shortest note

\# of notes

total length

min. space
$2700-3150 \mathrm{~Hz}$

$4000-4700 \mathrm{~Hz}$

$900-2000 \mathrm{~Hz}$

$0.26-0.38 \mathrm{~s}$

$0.04-0.33 \mathrm{~s}$

$2-3$

$0.45-0.84 \mathrm{~s}$

$0.075-0.20 \mathrm{~s}$
$1200-2120 \mathrm{~Hz}$

$4500-5000 \mathrm{~Hz}$

$2700-3300 \mathrm{~Hz}$

$0.21-0.36 \mathrm{~s}$

0.09-0.11s

2 (sometimes connected)

$0.34-0.51 \mathrm{~s}$

$0.00-0.04 \mathrm{~s}$ 

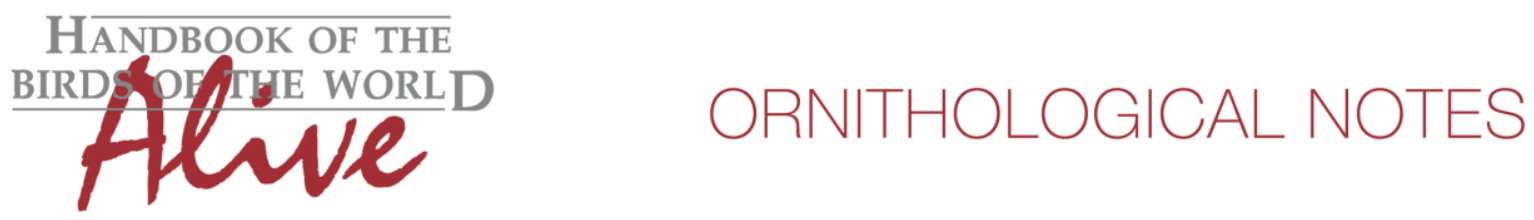

We can therefore conclude that day-time song differs as follows:

group 1 vs group 2: Central American and Caribbean group has a trilled day-time song with more notes (score 3-4), which are shorter (score 3) with hardly any spaces in between (score 3). When applying Tobias criteria this would lead to a total vocal score of about 6.

group 1 vs group 3: Central American and Caribbean group has a trilled day-time song with more notes (score 3-4) and shorter notes (score 3). Total score 6

group 2 vs group 3: Tumbes birds have a much narrower frequency range (score 2-3) with a longer pause in between notes (score 2-3). Total score about 5.

This note was finalized on 10th July 2015, using sound recordings available on-line at that moment. We would like to thank in particular the many sound recordists who placed their recordings for this species on XC and ML.

\section{References}

Tobias, J.A., Seddon, N., Spottiswoode, C.N., Pilgrim, J.D., Fishpool, L.D.C. \& Collar, N.J. (2010). Quantitative criteria for species delimitation. Ibis 152(4): 724-746.

\section{Recommended citation}

Boesman, P. (2016). Notes on the vocalizations of Tropical Pewee (Contopus cinereus). HBW Alive Ornithological Note 148. In: Handbook of the Birds of the World Alive. Lynx Edicions, Barcelona. (retrieved from http://www.hbw.com/node/932073 on 16 August 2016). 